\title{
Initialising finisher gaps in a hot strip mill
}

$\begin{array}{ccc}\text { Winston L. Sweatman } & \text { Graham } \text { Weir }^{2} & \text { Anton Gulley }^{3} \\ \text { Daniel Clarke } & \begin{array}{c}\text { Yasuhide Fukumoto }^{5} \\ \text { Sibylle Van Hove }\end{array} & \text { J. F. Harper }\end{array}$

(Received 13 September 2017; revised 6 May 2018)

\begin{abstract}
In the late stages of steel production in the New Zealand Steel hot strip mill, the sheets pass through a series of four pairs of rollers that squeeze the metal to the required thickness. The gaps between the pairs of rollers are controlled by controllers based upon a combination of models with feedback from measurements. New Zealand Steel brought a project to consider this process to the 2016 Mathematics-in-Industry New Zealand Study Group. The lines of investigation described include mathematical models based on the physics of the process, which have identified the primary parameters affecting steel processing between the rollers; and statistical analysis of data provided, revealing that the present electronic controllers improve target gauge over time. The first few metres of a strip are often outside acceptable thickness limits
\end{abstract}

DOI:10.21914/anziamj.v58i0.12433, (c) Austral. Mathematical Soc. 2018. Published 2018-05-19, as part of the Proceedings of the 2016 Mathematics and Statistics in Industry NZ Study Group. ISSN 1445-8810. (Print two pages per sheet of paper.) Copies of this article must not be made otherwise available on the internet; instead link directly to the DOI for this article. 
after going through the rollers. We diagnose likely causes and suggest possible cures.

Keywords: mathematics in industry, steel production

\section{Contents}

1 Introduction

M303

2 The hot strip mill roller finishing process

M305

3 Stress state between the rollers

M308

3.1 Vertically averaged stress model . . . . . . . . . . . M310

3.2 Perfect plasticity, slipline theory . . . . . . . . . . . M312

4 Radiative heating of a roller by hot steel

M313

5 Quasi-steady temperature profiles

M314

6 Transients

M315

7 Parametric sensitivity

M317

8 Active feedback

M317

9 Data Analysis

M317

10 Hybrid Learning Model

M322

11 Discussion and summary

M323

References

M324 


\section{Introduction}

Within New Zealand and Australia, there has been a long history of study group projects brought by New Zealand Steel or its parent company Bluescope Steel. In the eight years 2004-2011 there was an average of one project per year. The first three projects were in the first three study groups in New Zealand (MISG 2004-2006). Subsequently, in Australia, four projects were brought to Wollongong (MISG 2007-2009) and one to Melbourne (MISG 2011). These projects are listed in Table 1. The kind of modelling approach has varied. The project from MISG 2006 was statistical whereas others were deterministic in nature. The stage of the steel process modelled has also varied, from the early stages of steel production from iron sand where metalloid impurities are removed from the molten raw iron, through mechanical and thermal processing of the steel product, which change both the external and internal structures, to galvanisation of the finished steel sheet.

Japanese researchers participated in this study group (MINZ 2016) as part of an exchange with the Japanese Mathematics-in-Industry Study Group a month later. Since its beginning the Japanese Mathematics-in-Industry Study Group has enjoyed a close collaboration with the steel industry. Every year since the Japanese MISG started in 2010, Dr. Junichi Nakagawa, executive senior researcher, Nippon Steel and Sumitomo Metal Company has contributed excellent problems. These projects are listed in Table 2. The problems are not necessarily directly related to the company's main business of producing steels. Rather, the problems have been judiciously selected more broadly from mathematics and mathematical science, which may somehow be indirectly related with its business, so as to stimulate mathematicians, and, in particular, to attract young participants to these kinds of challenge.

The present project concerns the New Zealand Steel hot strip mill where slabs of steel are rolled into strips. At the end of the process the steel strips are passed through a final series of four pairs of rollers to shape them to the desired thickness or gauge. Several factors affect the final thickness including 
Table 1: New Zealand and Australian Mathematics-in-Industry Projects from the steel industry in the years 2004 to 2011 [17].

\begin{tabular}{ll}
\hline Study group & Project \\
\hline MISG 2004 & $\begin{array}{l}\text { Strip temperature in a metal coating line annealing } \\
\text { furnace [11] } \\
\text { MISG 2005 }\end{array}$ \\
& $\begin{array}{l}\text { Development of empirical relationships for metallurgi- } \\
\text { cal design of hot-rolled steel products [9] } \\
\text { Development of empirical relationships for the mechan- } \\
\text { ical properties of cold-rolled steel products [16] }\end{array}$ \\
MISG 2007 & $\begin{array}{l}\text { Strip track-off and buckling between transport rolls [3] } \\
\text { Cold point determination in heat-treated steel coils [10, }\end{array}$ \\
MISG 2008 & $\begin{array}{l}\text { 2, 18] } \\
\text { MISG 2009 }\end{array}$ \\
MISG 2009 slumping [1] & Metal coating deformation [6, 4, 5] \\
MISG 2011 & Recovery of vanadium during steel production [19] \\
\hline
\end{tabular}

the chemistry and temperature of the steel. The parameters for controlling the operation are the gaps between the top and bottom rollers of each set of rollers and the speed setting. When handling a single strip, the machinery requires initial settings before feedback is available to control operation. These are the subject of the project.

The MINZ study group considered this process using mathematical models (Section 3). This model-driven approach uses physical theory to construct simple models of the relevant key processes within the steel mill. One idea behind this approach was for the identification of parameters that have a significant impact on the gauge. A longer term goal could be to suggest improvements upon the current model. A second data-driven approach (Section 9) seeks to find the key parameters and items of significance by looking at data on strip production. In consultation with the MINZ team the industry representatives collated appropriate data from their large stores of 
Table 2: Japanese Mathematics-for-Industry Projects from the steel industry in the years 2010 to 2016 [21, 22, 14, 15, 12, 13, 8].

\begin{tabular}{ll}
\hline Study group & Project \\
\hline SGW 2010 & $\begin{array}{l}\text { Inverse problem from a multi-scale viewpoint utilising } \\
\text { a combination of stochastic, analytic, and geometric } \\
\text { modeling } \\
\text { Mathematical modeling for anomalous diffusion in soil } \\
\text { and report }\end{array}$ \\
SGW 2011 & $\begin{array}{l}\text { Brainstorming for getting an abstract framework for } \\
\text { thinking to tackle social and industrial problems } \\
\text { through a combination of geometry and algebra with } \\
\text { analysis }\end{array}$ \\
Mathematical models of traffic flow: mathematical \\
consideration regarding the relationship between con- \\
tinuous models and discrete types \\
Mathematics of materials informatics \\
Mathematical description of disordered structures in \\
crystal 2014 \\
Mathematical description concerning anisotropy of \\
grain boundary energy for metals
\end{tabular}

data which included cases where the head of a strip was out of specification. We begin with a description of the hot strip mill process (Section 2).

\section{The hot strip mill roller finishing process}

In the hot strip mill, to finish the process of rolling steel sheets (strips or bars) to their required thickness they pass through a set of four pairs of rollers (also called rolls). The reduction in thickness may be by up to $90 \%$ and occurs 
Figure 1: A steel strip passing between a pair of rollers [7, modified].

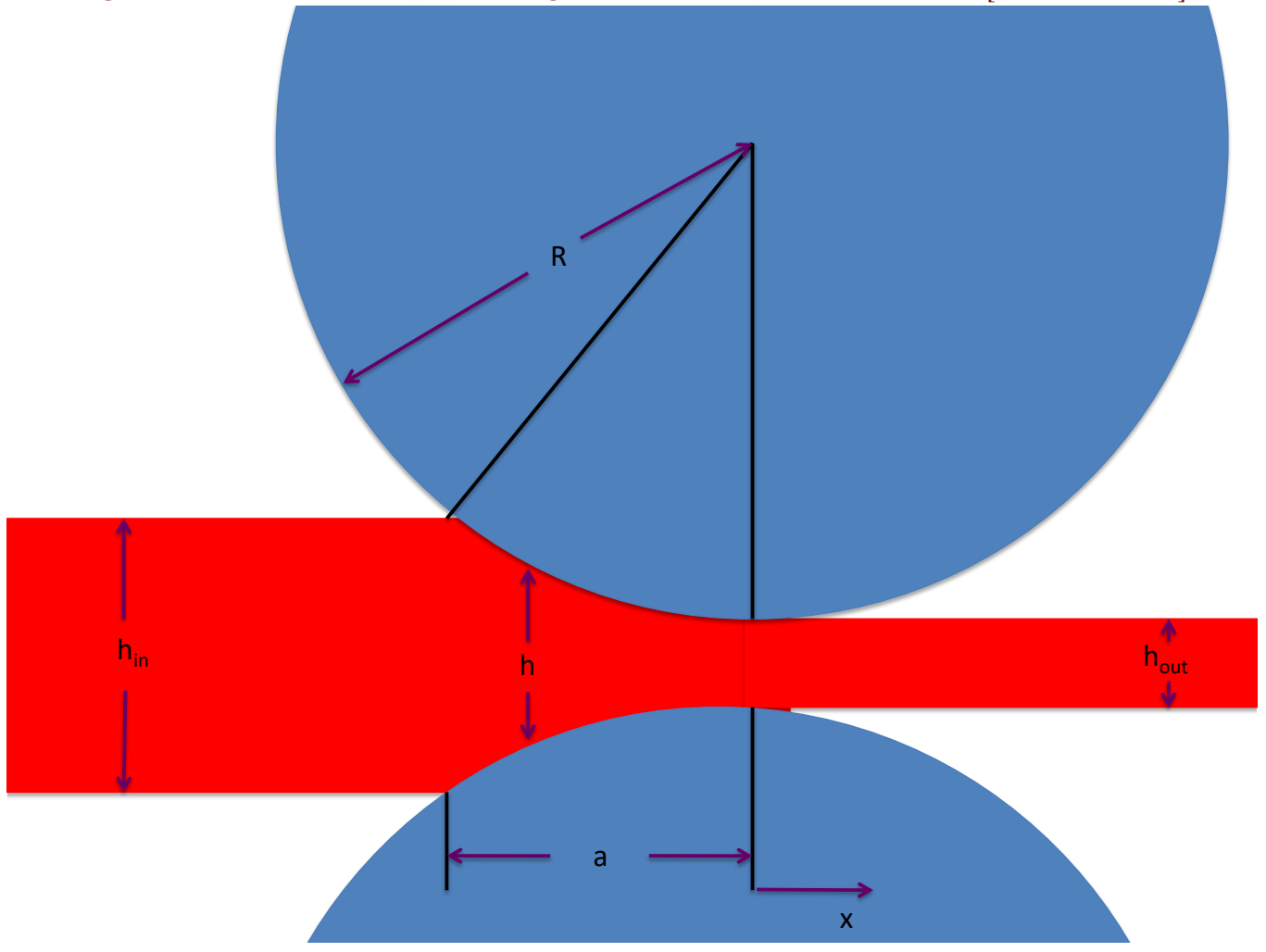

primarily in the first two rollers of the series. The last two rollers are used more for shape control. Figure 1 illustrates the geometry of a steel strip passing through a pair of rollers.

The roller machinery heats and wears with usage. The work rollers that shape the metal only last about twelve hours, and the larger rollers that drive these and hold them in position also need replacing at about eight-week intervals. During production strips are produced sequentially in lots. These differ in their specification to meet demand but also for better management of the 
roller machinery which heats and wears with usage. The numbers of strips in each lot may vary from single strips to tens of strips. Twenty would be a typical number. During the lifetime of a work roller, the strip lots are scheduled to start with a narrow strip lot, then increase to the broadest strips and finally more gradually taper again to narrow strips. There are about 80 to 140 strips per schedule.

Once a steel strip begins to emerge from the rollers its thickness is measured using X-ray gauge measurement. Dynamic feedback allows the roller gaps to be adjusted. This readily enables the thickness to be kept within specification in the main body of a strip. However, at the beginning (or head) of a strip, in the delay before this takes effect, the gap settings have to be predicted. This is where the finisher-gap set-up model is used. When the finisher-gap set-up model fails to produce sufficiently good settings the head of the strip is either further processed or scrapped resulting in wastage. Typical lengths for head, main body and tail portions of a strip are 20-50 m, $700 \mathrm{~m}$ and $20 \mathrm{~m}$, respectively.

The finisher-gap set-up model is constructed from several semi-empirical models. These involve a wide range of input parameters, such as the temperature of the incoming steel and the steel chemical composition, as well as a series of coefficients obtained from look-up tables for each of the four rollers. The models also include adjustments based on data collected while running the machinery. The system first calculates the expected yield strength of the material, and then the force and torque necessary to roll such a material to the desired thickness. As a consequence of mass conservation there is a discrepancy in steel speed before and after the flattening rollers. The model estimates these values using classical rolling theory. These model outputs finally feed into the calculation of the roller gap.

Between each successive strip of metal that is processed, the model refines estimates for roller gap thickness based on measurements from the previous bar. This is called strip-to-strip learning. Additionally the system is able to 'learn' between lots of similar steel products - that is steel with similar mate- 
rial composition and final geometry. This is termed lot-to-lot learning. The system's 'learning' ability is manifested in the models by the inclusion of additive and/or multiplicative learning terms. Whereas strip-to-strip learning is implemented into most of the sub-models, the lot-to-lot learning terms appear in the calculations of the yield stress, rolling torque and metal temperature.

In practice, the heads of second and later strips within a lot usually meet specification. In particular this means being within plus or minus $5 \%$ of the target gauge. The challenge is to get the head of the first strip within a lot to meet the specification. Currently about $5 \%$ of these heads are out of specification. As the issue occurs in the first strip in a lot, it has been hypothesised within the steel industry that the strip-to-strip learning terms are well estimated by the system since strips after the first in lot are generally within specification. However, the industry considers the lot-to-lot learning terms are not as well estimated and could be correlated with the error between the desired gauge and the actual gauge. In some cases it may be months before a lot specification is repeated and lot-to-lot learning implemented. In contrast strip-to-strip learning is immediate and adjusts the setting for the strip following the current one regardless of whether it has the same specification.

Table 3 lists the parameters used by the MINZ team in their models. The steel properties are those of 316 stainless steel. Other values are typical for the steel plant.

\section{Stress state between the rollers}

As the steel bar enters and passes through the rollers, its stress state moves from a wholly elastic state, to a partially elastic-plastic state. On exit from the rollers, the stress state returns to a wholly elastic state. The stresses increase rapidly elastically to the plastic limit, after which they remain roughly constant as the shape of the metal bar deforms plastically. On exit from the 
Table 3: Parameters and their typical values

\begin{tabular}{|c|c|c|c|}
\hline & Description & Value & Unit \\
\hline$a$ & length of steel engaged between rollers & 0.06 & $\mathrm{~m}$ \\
\hline$A$ & nominal area & - & $\mathrm{m}^{2}$ \\
\hline C & specific heat of steel & 500 & $\mathrm{~J} \mathrm{~kg}^{-1} \mathrm{~K}^{-1}$ \\
\hline $\mathrm{D}$ & thermal diffusivity of steel & $5 \cdot 10^{-6}$ & $\mathrm{~m}^{2} \mathrm{~s}^{-1}$ \\
\hline $\mathrm{F}$ & vertical force of a roller & $2 \cdot 10^{5}$ & $\mathrm{~N}$ \\
\hline $\bar{h}$ & mean steel thickness between rollers & 0.01 & $\mathrm{~m}$ \\
\hline$h_{\text {gap }}$ & initial gap between rollers with no metal & 0 & $\mathrm{~m}$ \\
\hline$h_{\text {in }}$ & steel thickness entering rollers & 0.01 & $\mathrm{~m}$ \\
\hline$h_{\text {out }}$ & steel thickness exiting rollers & 0.007 & $\mathrm{~m}$ \\
\hline JE & radiative heat flux & $8 \cdot 10^{4}$ & $\mathrm{~J} \mathrm{~m}^{-2} \mathrm{~s}^{-1}$ \\
\hline$k_{M}$ & mill modulus & $3 \cdot 10^{7}$ & $\mathrm{~N} \mathrm{~m}^{-1}$ \\
\hline $\mathrm{K}$ & thermal conductivity of steel & 20 & $\mathrm{~W} \mathrm{~m}{ }^{-1} \mathrm{~K}^{-1}$ \\
\hline$l$ & length around roller boundary & 2 & $\mathrm{~m}$ \\
\hline $\mathrm{p}$ & pressure along steel between rollers & $10^{6}$ & $\mathrm{~Pa}$ \\
\hline $\mathrm{P}$ & power needed for running one roller & $4-6 \cdot 10^{6}$ & $\mathrm{~W}$ \\
\hline $\mathrm{R}$ & roller radius (first and second rollers) & $0.3,0.6$ & $\mathrm{~m}$ \\
\hline$s$ & distance inside roller from its surface & & $\mathrm{m}$ \\
\hline$t_{c}$ & contact time of roller with strip & $10^{-2}$ & $\mathrm{~s}$ \\
\hline $\mathrm{T}$ & Celsius temperature & & ${ }^{\circ} \mathrm{C}$ \\
\hline $\mathrm{T}_{\mathrm{b}}$ & roller inner boundary layer temperature & 100 & ${ }^{\circ} \mathrm{C}$ \\
\hline $\mathrm{T}_{\mathrm{c}}$ & surface temperature of cooled roller & 25 & ${ }^{\circ} \mathrm{C}$ \\
\hline $\mathrm{T}_{\mathrm{s}}$ & surface temperature of heated roller & 450 & ${ }^{\circ} \mathrm{C}$ \\
\hline $\mathrm{T}_{\mathrm{K}}$ & absolute (Kelvin) temperature of the steel strip & 1100 & K \\
\hline$v$ & roller boundary speed & 8 & $\mathrm{~ms}^{-1}$ \\
\hline$x$ & horizontal distance between rollers & $10^{-2}$ & $\mathrm{~m}$ \\
\hline$x_{R}$ & roller length & 750 & $\mathrm{~m}$ \\
\hline$y$ & vertical distance between rollers & $10^{-2}$ & $\mathrm{~m}$ \\
\hline Y & Tresca yield stress for simple tension & 200 & $\mathrm{MPa}$ \\
\hline$z$ & horizontal distance across roller's midsection & 1 & $\mathrm{~m}$ \\
\hline Z & width of steel bar & 1 & $\mathrm{~m}$ \\
\hline$\alpha$ & coefficient of linear thermal expansion & $10^{-5}$ & $K^{-1}$ \\
\hline$\delta$ & thermal boundary layer thickness & $4 \cdot 10^{-4}$ & $\mathrm{~m}$ \\
\hline$\delta R$ & initial roller gap & $4 \cdot 10^{-3}$ & $\mathrm{~m}$ \\
\hline$\Delta \mathrm{h}$ & roller elastic strain displacement & $2 \cdot 10^{-4}$ & $\mathrm{~m}$ \\
\hline$\Delta \mathrm{T}$ & radiative temperature rise at roller surface & 3 & $\mathrm{~K}$ \\
\hline$\rho$ & density of steel & 8000 & $\mathrm{~kg} \mathrm{~m}^{-3}$ \\
\hline$\sigma$ & Stefan-Boltzmann constant & $5.67 \cdot 10^{-8}$ & $\mathrm{~N} \mathrm{~m}^{-1} \mathrm{~K}^{-4}$ \\
\hline
\end{tabular}


rollers, the stress state returns rapidly to a fully elastic state.

Deformations in the elastic state are restricted to strains $\Delta h / h$ of around 0.001, and are controlled largely by Young's modulus, which is of order $10^{11} \mathrm{~Pa}$. For steel thicknesses $\mathrm{h}$ of around $1 \mathrm{~cm}$, the elastic displacements $\Delta \mathrm{h}$ are less than about $10^{-5} \mathrm{~m}$, which is smaller than the acceptable thickness variations of around $5 \cdot 10^{-5} \mathrm{~m}$. Thus elastic deformations in the rolled steel are modest, and are ignored in this paper, suggesting the use of wholly plastic models.

We assume that the stress state is essentially a two-dimensional problem, being independent of distance across the steel bar. Let $\sigma_{1}, \sigma_{2}$ be the principal stress components in a vertical plane along the steel strip, then the pressure is $\left(\sigma_{1}+\sigma_{2}\right) / 2$, and so the deviatoric principal stresses are $\pm\left(\sigma_{1}-\sigma_{2}\right) / 2$. Supposing that $\sigma_{1}$ is the maximum principal stress and $\sigma_{2}$ the minimum principal stress, then the Tresca yield condition is

$$
\sigma_{1}-\sigma_{2}=\mathrm{Y},
$$

where $Y$ is the corresponding yield stress. The Tresca condition is widely used to describe plastic failure in an isotropic material. It assumes plastic failure occurs when the difference between the maximum and minimum principal stresses exceeds a fixed value.

\subsection{Vertically averaged stress model}

Perhaps the simplest model of stresses in a thin hot rolled steel bar, pressed between two large elastic rollers, was developed by von Karman in 1925 [20]. Von Karman considered only mean vertical stresses, and assumed that the steel in the region between the rollers was wholly plastic, with the shear stress at the roller surfaces equalling the yield stress $\mathrm{Y}$.

Let $h_{\text {in }}$ and $h_{\text {out }}$ be the total vertical input and outlet thicknesses of steel between the rollers (Figure 1), then the horizontal distance a between these 
two heights is approximately

$$
a \approx \sqrt{R\left(h_{\text {in }}-h_{\text {out }}\right)} ;
$$

and, since the roller radius $R$ is large relative to the steel bar thickness $h$,

$$
\mathrm{h}(\mathrm{x}) \approx \mathrm{h}_{\text {out }}+\frac{\mathrm{x}^{2}}{2 \mathrm{R}} .
$$

Here $x$ is the distance along the steel strip, being zero where the steel emerges from the roller.

The mean thickness of steel between the rollers is approximated by

$$
\overline{\mathrm{h}} \approx \frac{\mathrm{h}_{\mathrm{in}}+\mathrm{h}_{\mathrm{out}}}{2} .
$$

Von Karman's assumption of a mean vertical stress, predicts the pressure $\mathrm{P}$ between the rollers increases approximately linearly from $Y$ at $x=-a$ for a distance of $\mathrm{a} / 2$, and then decreases linearly to $\mathrm{Y}$ at the exit

$$
\mathrm{P} \approx \begin{cases}Y\left(1+\frac{\mathrm{a}+x}{\mathrm{~h}}\right), & -\mathrm{a}<x<-\frac{\mathrm{a}}{2}, \\ Y\left(1-\frac{x}{h}\right), & -\frac{\mathrm{a}}{2}<x<0 .\end{cases}
$$

The join in the pressure distribution in equation (5) at $x=-a / 2$ is called the neutral point, where the average steel horizontal velocity equals that of the outer cylinder surface. Before the neutral point, steel moves slower than the cylinder surface, and is pulled by friction. After the neutral point, while still between the two rollers, the steel moves faster than the cylinder surface, and is opposed by friction.

The principal stresses then are approximately

$$
\sigma_{1}=\mathrm{P}+\frac{\mathrm{Y}}{2}, \quad \sigma_{2}=\mathrm{P}-\frac{\mathrm{Y}}{2} .
$$


The total force $\mathrm{F}$ on one roller is approximately

$$
\mathrm{F} \approx \mathrm{YZa}\left(1+\frac{\mathrm{a}}{2\left(\mathrm{~h}_{\mathrm{in}}+\mathrm{h}_{\text {out }}\right)}\right),
$$

where $\mathbf{Z}$ is the width of the steel sheet. The operating gap between the two rollers comprises the initial gap $h_{\text {gap }}$ set before steel flows between the rollers, and the additional gap $F / k_{M}$ formed in response to metal flowing between the rollers, where $F$ is the force acting on the rollers by the flowing steel, and $k_{M}$ is the mill modulus, a spring constant for the roller system, so that

$$
h_{\text {out }}=h_{\text {gap }}+\frac{F}{k_{M}} .
$$

Comparing (8) and (7) shows that the required exit thickness $h_{\text {out }}$ equals $h_{\text {gap }}$, set by a NZ Steel operator as informed by Toshiba software, and an additional term proportional to the yield stress. Yield stress is defined as deformation resistance by the Toshiba and NZ Steel Handbooks used by the industry.

\subsection{Perfect plasticity, slipline theory}

The assumption that the steel is wholly plastic between the rollers is not true in slipline theory [7]. Instead there are several different regimes, originating from elastic zones between the rollers. Typically there is a small non-slip region at the surface of rollers at the entry points. Then there is an elastic region about the neutral point, extending away from the roller walls and into the steel. Plastic flow occurs between the elastic zones between the rollers. The elastic regions are transported rigidly with the roller surface velocity. 


\section{Radiative heating of a roller by hot steel}

When a hot steel strip approaches a roller the radiative heat flux $J_{E}$ from the strip is approximately

$$
\mathrm{J}_{\mathrm{E}}=\sigma \mathrm{T}_{\mathrm{K}}^{4}=\left(5.67 \cdot 10^{-8} \mathrm{~J} \mathrm{~m}^{-2} \mathrm{~s}^{-1} \mathrm{~K}^{-4}\right)(1100 \mathrm{~K})^{4},
$$

where $\sigma$ is the Stefan-Boltzmann constant and $T_{K}$ is the absolute temperature of the strip. That heats up the roller, which is much cooler than $T_{K}$, so we ignore radiation from the roller. The roller radius is much greater than the thermal boundary-layer thickness at its surface, so we also ignore roller curvature when calculating the boundary layer. The temperature rise $\Delta \mathrm{T}$ (due to radiative heating) above the mean temperature of the roller obeys the differential equation

$$
\frac{\partial \Delta T}{\partial t}=D \frac{\partial^{2} \Delta T}{\partial s^{2}} \quad \text { in } s \geqslant 0,
$$

where $s$ is the distance into the roller from its surface, $t$ is the time since that part of the roller became exposed to the hot strip, and $\mathrm{D}=\mathrm{K} / \rho \mathrm{C}$ is the thermal diffusivity of the roller. The initial and boundary conditions are approximately

$$
\begin{gathered}
\Delta \mathrm{T}=0 \quad \text { at } \mathrm{t}=0, \\
\frac{\partial \Delta \mathrm{T}}{\partial \mathrm{s}}=\frac{\mathrm{J}_{\mathrm{E}}}{\mathrm{K}_{\mathrm{T}}} \quad \text { at } \mathrm{s}=0,
\end{gathered}
$$

where $\mathrm{K}_{\mathrm{T}}$ is the roller's thermal conductivity. The solution is

$$
\frac{\partial \Delta T}{\partial s}=\frac{J_{E}}{K_{T}} \operatorname{erfc}\left(\frac{s}{2 \sqrt{\mathrm{Dt}}}\right) \quad \text { in } s \geqslant 0 .
$$

Because $\int_{0}^{\infty} \operatorname{erfc}(x) d x=1 / \sqrt{\pi}$, the radiative surface temperature rise is

$$
\Delta \mathrm{T}=\left(2 \mathrm{~J}_{\mathrm{E}} / \mathrm{K}_{\mathrm{T}}\right) \sqrt{\mathrm{Dt} / \pi} \text { at } \mathrm{s}=0 .
$$


If the roller moves at $v=8 \mathrm{~m} / \mathrm{s}$ and $0.5 \mathrm{~m}$ of roller is exposed to the incoming strip, then $\mathrm{t}$ is of order $0.1 \mathrm{~s}$. The parameters in Table 3 give $\Delta \mathrm{T} \approx 3 \mathrm{~K}$. Similar heating by the outgoing strip will give total radiative heating of the roller of about $6 \mathrm{~K}=6{ }^{\circ} \mathrm{C}$.

For comparison the total heating of the roller is of order $30^{\circ} \mathrm{C}$ from the NZ Steel estimates of approximate ambient temperature $\left(25^{\circ} \mathrm{C}\right)$ and roller temperature $\left(55^{\circ} \mathrm{C}\right)$. Therefore radiative heating of the roller is small by comparison with the conductive heating that happens when roller and strip are in contact.

\section{Quasi-steady temperature profiles}

The previous section shows that the effect of radiative heat transport is relatively small, establishing that we need only consider conductive heat transport. In this section, we consider conductive heat transport across thermal boundary layers in the hot steel and about the roller boundary.

In the small region where the hot steel strip contacts the roller boundary, high fluxes transport heat from the strip into the rollers. If the thermal properties of the strip and rollers are similar, then their boundary layer thicknesses $(\delta)$ will also be similar. The flux of heat from strip to roller will then equal $\mathrm{K}\left(\mathrm{T}_{\mathrm{h}}-\mathrm{T}_{\mathrm{s}}\right) / \delta=\mathrm{K}\left(\mathrm{T}_{\mathrm{s}}-\mathrm{T}_{\mathrm{b}}\right) / \delta$, where $\mathrm{T}_{\mathrm{s}}$ is the temperature at the roller (and strip) surface, $T_{h}$ is the steel strip temperature just before reaching the rollers and within its thermal boundary layer when between the rollers, and $T_{b}$ is the roller temperature just within its own thermal boundary layer. Hence

$$
\mathrm{T}_{\mathrm{s}}=\frac{1}{2}\left(\mathrm{~T}_{\mathrm{h}}+\mathrm{T}_{\mathrm{b}}\right)
$$

We now consider a thermal boundary layer thickness $\delta$ around the roller boundary, starting from zero thickness where the roller first contacts the hot steel, and increasing around the boundary of the roller,

$$
\delta=2 \sqrt{\mathrm{Dl} / v},
$$


where $\mathrm{D}$ is thermal diffusivity, $l$ is a length variable around the roller boundary, and $v$ is the outer roller speed.

We assume that the temperature on the outside of the boundary layer is $T_{s}$ over the length $a$ of contact between the roller and steel, and $T_{c}$ elsewhere; and $T_{b}$ on the inner surface of the boundary layer.

The rate of change of heat $\dot{\mathrm{Q}}_{\text {in }}$ into the roller then is

$$
\dot{Q}_{\text {in }}=Z \int_{0}^{a} J_{\text {in }} d l=\frac{K Z\left(T_{s}-T_{b}\right) \sqrt{v}}{2 \sqrt{D}} \int_{0}^{a} \frac{d l}{\sqrt{l}}=\frac{K Z\left(T_{s}-T_{b}\right) \sqrt{v a}}{\sqrt{D}} .
$$

The rate of change of heat $\dot{\mathrm{Q}}_{\text {out }}$ out of the roller is

$$
\begin{aligned}
\dot{Q}_{\text {out }} & =Z \int_{a}^{2 \pi R} J_{\text {out }} d l=\frac{K Z\left(T_{b}-T_{c}\right) \sqrt{v}}{2 \sqrt{D}} \int_{a}^{2 \pi R} \frac{d l}{\sqrt{l}} \\
& =\frac{K Z\left(T_{b}-T_{c}\right) \sqrt{v}(\sqrt{2 \pi R}-\sqrt{a})}{\sqrt{D}} .
\end{aligned}
$$

The inner boundary layer temperature $\mathrm{T}_{\mathrm{b}}$ is chosen so that $\dot{\mathrm{Q}}_{\text {in }}=\dot{\mathrm{Q}}_{\text {out }}$, and, from equations (15), (17) and (18),

$$
T_{b}=T_{c}+\frac{\left(T_{s}-T_{c}\right) \sqrt{a}}{\sqrt{2 \pi R}}=\frac{T_{c}+\sqrt{a / 2 \pi R}\left(T_{h} / 2-T_{c}\right)}{1-\sqrt{a / 8 \pi R}} .
$$

Values from Table 3 indicate that the roller temperature $T_{b}$, just inside the thermal boundary layer, can increase to around $100^{\circ} \mathrm{C}$. Over time, the interior of the roller will tend to a temperature of $T_{b}$.

\section{Transients}

An estimate of the time $t$ for the central axis of the roller to approach a temperature of $T_{b}$ is

$$
\mathrm{t} \approx \frac{\mathrm{R}^{2}}{\mathrm{D}}
$$


and parameter values from Table 3 suggest $\mathrm{t} \approx 10^{4} \mathrm{~s}$, or about 4 hours.

After this time, the central part of one of the first rollers is at a temperature of $T_{b}$, and its radius $R$ will have increased through thermal expansion by around $\delta R \approx \alpha R\left(T_{b}-T_{c}\right)$. Parameter values from Table 3 suggest $\delta R \approx$ $0.3 \mathrm{~mm}$, which is significant relative to acceptable tolerances for sheet thickness. However, the outer vertical edges of the roller, which do not physically contact the hot steel, will remain cooler than $\mathrm{T}_{\mathrm{b}}$, and consequently will not expand as much, causing the central part of the roller to 'crown'. That is, the central part of the rollers becomes thicker than at the edges. The central crown will reduce the thickness of the inner part of the sheet.

The central parts of the sheet steel will then be thinner than the outer parts, on passing through the first set of rollers, after several hours of operation. However, on passing through the second set of rollers, the outer thicker parts of the sheet steel are preferentially plastically compressed, and a more uniform thickness achieved for the final sheet steel.

The second set of rollers correct for the effects of crowning in the first rollers, until they also begin to crown, which happens after about a day, because of the greater radius of the second set of rollers.

To an extent these crowning effects are controlled by the NZ Steel practices. Rollers are replaced after twelve hours, and lots are strategically scheduled in order of their width (cf. Section 2).

After cooling, the outer edges of the removed rollers have greater radius, due to less wear there. These outer edges are then ground down, to achieve a roller with a uniform radius. The rollers are reused, but on each successive grinding of the outer edges, the rollers reduce their radii, and eventually the rollers require more serious maintenance. Throughout this gradual reduction in roller radius, the mechanical properties of the total roller system vary, and initial roller gaps need corresponding adjustments. 


\section{Parametric sensitivity}

Output gauge is required to be within $5 \%$. For $2 \mathrm{~mm}$ gauge steel, this requires tolerances within $0.1 \mathrm{~mm}$. There is a natural variation of around $0.01 \mathrm{~mm}$ in gauge, due to elastic deformation and temperature variations.

From (7), if either $\mathrm{F}$ or $\mathrm{Y}$ is fixed, and errors in $\mathrm{h}_{\text {out }}$ are less than the tolerance of $5 \%$, then the error in either $\mathrm{Y}$ or $\mathrm{F}$ respectively must be less than about $7 \%$. For example, if $\mathrm{Y}$ varies by around 50\% during usual operation of the plant, then a table with around seven look-up cases for yield stress should be capable of delivering the required accuracy in output gauges.

\section{Active feedback}

In principle, active feedback is obtained from measuring the forces on the rollers. Since $30 \mathrm{~m}$ of steel has to move through the system before the short term learning begins, the minimum losses when corrections are needed will exceed $30 \mathrm{~m}$. In contrast, if corrections began at the first rollers (the F1 rollers), then in principle, the minimum losses of steel product could be several metres, reducing steel losses by an order of magnitude. This idea is somewhat beyond the main remit of the project and has not been explored further.

\section{Data Analysis}

The New Zealand Steel representatives provided four months of 2016 data from the hot strip mill. This data set contained 267 different variables on each steel bar that passed through the hot strip mill. The data included measurements of different physical properties of the steel strips and the mill as well as the values of many of the learning terms. In particular, there is a measurement of the gauge of the strip approximately $10 \mathrm{~m}$ along the strip. 
This measurement provides an estimate of the gauge at the head end of the strip before the dynamic controller has had an opportunity to adjust the strip thickness and therefore this measurement is directly related to the model. This data did not include information on the temperature model and so this model could not be investigated.

The data was first processed by removing outliers in the head-end gauge error. A variety of reasons were identified as the cause of these outliers. These include instances where the mill had to be restarted and when the strip spent longer than expected in the coiling box prior to the finishing mill, and consequently cooled more than expected. Data from warm rolling (plates) was also removed as this was not of interest. A subset of the data was identified that contained the first strips in a lot together with their subsequent (second) strips in the lot. This data was used by the MINZ study group to attempt to identify problems with the current model used by NZ Steel and seek opportunities for improvement.

Figure 2 plots the gauge error of the first strip in a lot against the gauge error in the subsequent strip. The figure shows that the head-end gauge error is, on average, significantly reduced from the first strip to the second strip. The cause of this improvement is the strip-to-strip learning that takes place in the model between the first and second strips in a lot. From the first strip to the second strip, the errors have reduced by $50 \%$ on average. Figure 2 also shows that the errors in the first two strips are correlated. Although this study is primarily interested in reducing the error of the first strip in the lot, this information shows that the error in the second strip may be estimated from the error in the first strip and further improvements for the gauge in the second strip may be possible.

Figure 2 also shows that the measurement error of the first strip is approximately normally distributed. This means that there are no clear indications that the model has failed and therefore that fractional improvements in the model must be made in order to reduce the number of strips with gauge error above accepted tolerance. 
Figure 2: The change in the head-end gauge error from the first to the second strip in a lot. The error is defined as target gauge minus measured gauge. The contours show the approximate density of points.

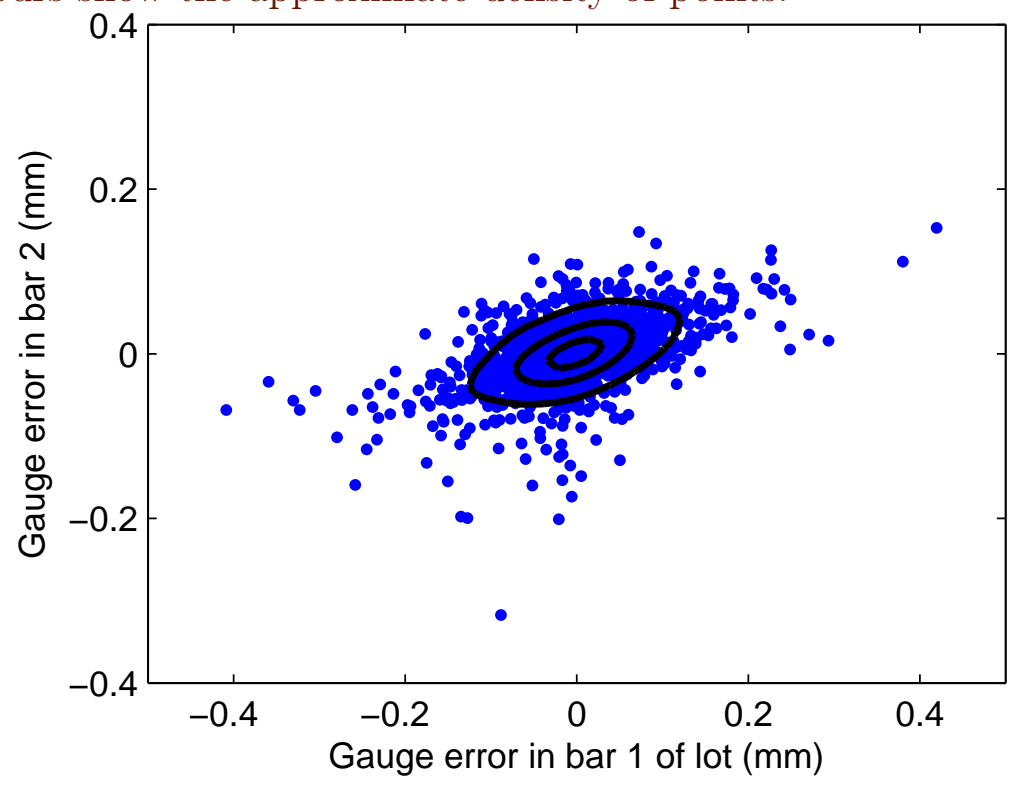

Figure 3 plots the change in the strip-to-strip learning term from strip 1 to strip 2 of a lot against the gauge error in the first strip. These parameters have a Pearson correlation coefficient of -0.2 . In the Toshiba roller gap model this strip-to-strip learning term is an additive learning term that changes the roller gap of the mill. The correlation indicates that, as expected, this learning term corrects for some of the gauge error in strip 1 of the lot. However, the correction is quite small and the change in the strip-to-strip learning term can only account for $3 \%$ of the total variation of the gauge error. This means that the majority of the improvement in head-end gauge error between strip 1 to strip 2 (Figure 2) is due to other learning terms.

The most significant correlations in the data were between the gauge error and the change in the rolling-force learning terms from strip 1 to strip 2 . 
Figure 3: Scatter plot of the gauge error of the first strip in a lot versus the change in the additive roller-gap strip-to-strip learning term.

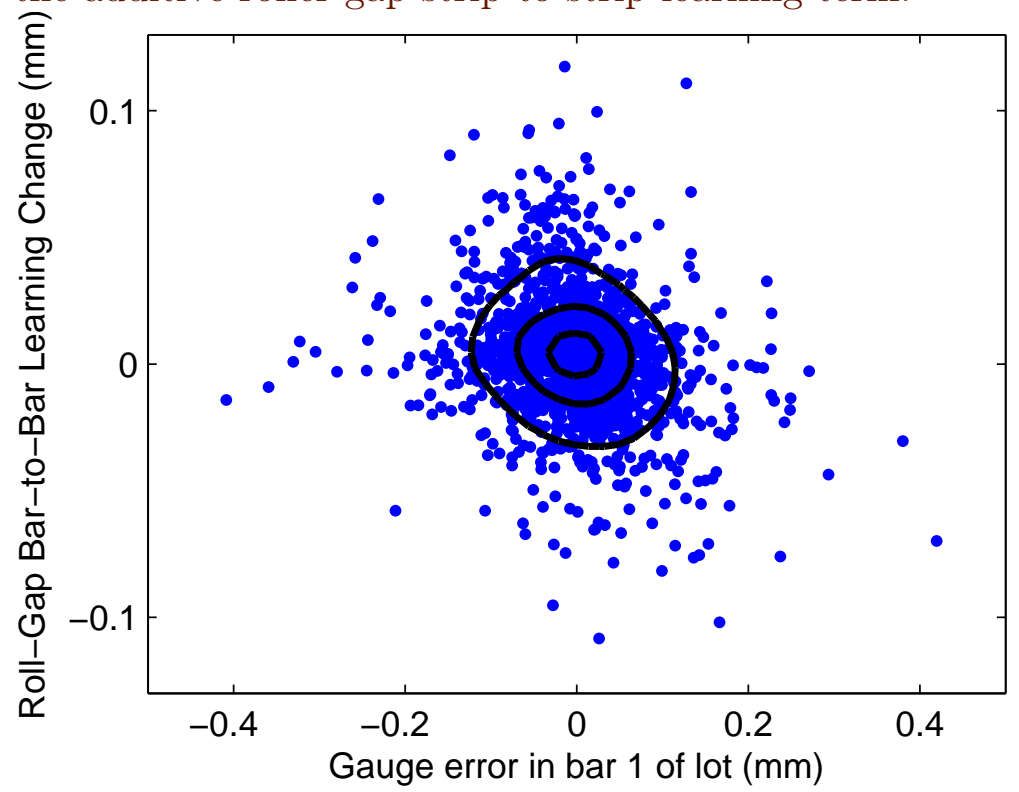

In particular, these correlations are large for the first pair of rollers. The correlation between the change in this strip-to-strip learning term for the second roller and the percentage gauge error is 0.3. The relationship is illustrated in Figure 4.

The correlations in the rolling-force strip-to-strip learning terms suggest that there is scope for improvement in the rolling-force model. One option would be to include a lot-to-lot learning term in the rolling force model, although this would require further investigation as to exactly how this is to be done. A regression analysis is used to investigate the potential effect. This regression analysis performs a linear fit of the percentage gauge error using the change in rolling-force strip-to-strip learning terms for each of the four rollers. The result is that these parameters account for $10 \%$ of the total variation (standard deviation) of the percentage gauge error and result in a $40 \%$ reduction in the 
Figure 4: Scatter plot of the percentage gauge error of the first strip in a lot versus the change in the rolling-force strip-to-strip learning term in the second roller.

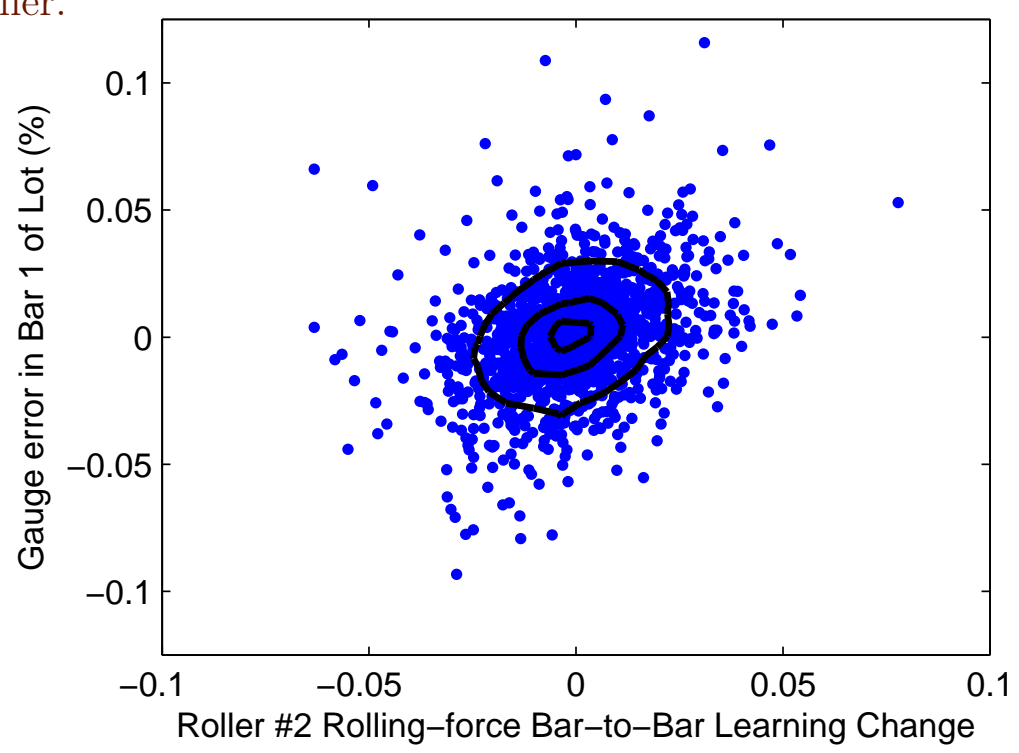

number of strips that are more than $3 \%$ out of tolerance.

Many further scatter plots and regression analyses were investigated in order to find parameters that correlated with the gauge error. No more meaningful correlations with gauge error were found. This is likely because the learning terms have already accounted for any linear correlations that may arise. A future step would be to investigate nonlinear effects. However, owing to the inherent complexity of the model as well as the large number of parameters involved, this would first require a much more detailed analysis and understanding of the current (Toshiba) models. 


\section{Hybrid Learning Model}

The current approach to initially target the final gauge uses a long-term learning model based on geometrical, physical, chemical and temperature data. Once gauge measurements are available from the X-ray at the end of the rollers, the short-term learning-control process begins, using only current measurements. Experience shows that the most difficult step is implementing the long-term learning model, which produces the majority of gauge failures. Once the short-term learning is complete, the total changes made in obtaining the final gauge may be assessed.

Following the first lot after a change of rollers, a hybrid approach could be used. The long-term learning prediction for the next lot could be modified so as to use the present information on gauge thicknesses, and aim to invoke changes in gauge from current gauge settings, to the required new gauge. For example, if a change in gauge from $2 \mathrm{~mm}$ to $3 \mathrm{~mm}$ is required, then the hybrid approach would seek to make a $1 \mathrm{~mm}$ change in gauge from current settings, rather than the long-term learning approach of setting up for a $3 \mathrm{~mm}$ gauge from scratch. In this example, the hybrid model seeks a change of gauge one third of the gauge involved in the long-term learning model. An attractive aspect is that essentially relative changes in yield stress are needed, rather than absolute estimates.

A hybrid model could be implemented within NZ Steel, and assessed against the current Toshiba/NZ Steel model, comparing the predictions of the hybrid model against the final results obtained from the existing long-term and short-term learning models. A decision to implement the hybrid model could then be made. An especial attraction of the hybrid model is its simplicity, compared to the current complexity of the long-term learning model. 


\section{Discussion and summary}

This project concerned the process of rolling sheet steel in the late stages of steel production, and specifically the challenges arising in predicting initial settings. After describing the overall process, the early part of our paper considers the physical model in more detail. We have identified possible sources of significant error in the long-term learning models, each of which is capable of resulting in gauge being outside the required $5 \%$ tolerance

- Delay in the coil box Delaying steel products in the coil box prior to rolling results in lower steel temperatures, perhaps by $50^{\circ} \mathrm{C}$ lower than expected. This causes higher yield stresses, reduced extensions, and greater steel thicknesses.

- Thermal expansion of the rollers After about 12 hours of operation, sufficient heat flows into the rollers to increase their diameter by thermal expansion by a fraction of a millimetre. This expansion is localised in the central part of the roller, resulting in crowning, additional wear, and reducing the steel thickness. To an extent this problem has been managed in practice by replacing rollers after 12 hours and by carefully scheduling the ordering of lots by the strip widths.

An analysis of data provided by NZ Steel found correlations between the data that suggest that there is further scope for improving the long-term learning models.

Acknowledgements We are grateful to the New Zealand Steel industry representatives Rory Kimber and Kevin Niederberger for bringing this problem to MINZ-2016 and for their valuable input. We also acknowledge Paul Teal for his contribution as a member of the project team. The organisation and hospitality at Victoria University of Wellington was greatly appreciated. 


\section{References}

[1] Anderssen, R., Fowkes, N., Hickson, R., McGuinness, M.: Analysis of coil slumping. In: T. Marchant, M. Edwards, G. Mercer (eds.), Proceedings of the 2009 Mathematics and Statistics in Industry Study Group, pp. 90-108, University of Wollongong, Australia ISBN: 978-1-74128-181-1 (2010) M304

[2] Barry, S.I., Sweatman, W.L.: Modelling heat transfer in steel coils. ANZIAM J. 50, pp. C668-C681 ISSN: 1446-8735 (2009) M304

[3] Fraser, W.B., Macaskill, C., McGuinness, M., Thornton, A.: Strip track-off and buckling between transport rollers. In: T. Marchant, M. Edwards, G. Mercer (eds.), Proceedings of the 2007 Mathematics and Statistics in Industry Study Group, pp. 13-31, University of Wollongong, Australia ISBN 978-0-646-48555-3 (2008) M304

[4] Hocking, G.C., Sweatman, W.L., Fitt A.D., Breward, C.: Deformations during jet-stripping in the galvanizing process. Journal of Engineering Mathematics, 70, 297-306 doi:10.1007/s10665-010-9394-8 (2011) M304

[5] Hocking, G.C., Sweatman, W.L., Fitt A.D., Breward, C.: Deformations arising during air-knife stripping in the galvanisation of steel. In: M. Günther, A. Bartel, M. Brunk, S. Schöps, M. Striebel (eds.), Progress in Industrial Mathematics at ECMI 2010, Mathematics in Industry 17, Springer Berlin Heidelberg, 311-317 doi:10.1007/978-3-642-25100-9_36 (2012) M304

[6] Hocking, G.C., Sweatman, W.L., Roberts, M.E., Fitt A.D.: Coating Deformations in the continuous hot-dipped galvanizing process. In: T. Marchant, M. Edwards, G. Mercer (eds.), Proceedings of the 2009 Mathematics and Statistics in Industry Study Group, pp. 75-89, University of Wollongong, Australia ISBN: 978-1-74128-181-1 (2010) M304 
[7] Johnson, K.L.: Contact Mechanics, Cambridge University Press, Cambridge, pp 452 ISBN 0-521-34796-3 (1987) M306, M312

[8] Koiso, M., Ninomiya., Y., Yamamoto, M. (eds.): Study Group Workshop 2016, MI Lecture Note Series, 71, 92-111, ISSN:2188-1200 (2016) M305

[9] Marchant, T., Nickerson, A., Scott, D., Taylor, S.: Development of empirical relationships for metallurgical design of hot-rolled steel products. In: G.C. Wake (ed.), Proceedings of the 2005 Mathematics in Industry Study Group, pp. 53-72, Massey University, New Zealand ISBN 0-473-10423-7 (2005) M304

[10] McGuinness, M., Sweatman, W.L., Baowan, D., Barry, S.I.: Annealing Steel Coils. In: T. Marchant, M. Edwards, G. Mercer (eds.), Proceedings of the 2008 Mathematics and Statistics in Industry Study Group, pp. 61-80, University of Wollongong, Australia ISBN 978-0-646-50544 (2009) M304

[11] McGuinness, M., Taylor, S.: Strip temperature in a metal coating line annealing furnace. In: G.C. Wake (ed.), Proceedings of the 2004 Mathematics in Industry Study Group, pp. 23-45, Massey University, New Zealand ISBN 0-476-01130-2 (2005) M304

[12] Nishii, R., Okada, K., Kajiwara, K., Takagi, T., Wakayama, M., Waki, H., Yamamoto, M. (eds.): Study Group Workshop 2014, MI Lecture Note Series, 59, 92-110, ISSN:2188-1200 (2014) M305

[13] Okada, K., Fujisawa, K., Shirai, T., Wakayama, M., Waki, H., Broadbridge, P., Yamamoto, M. (eds.): Study Group Workshop 2015, MI Lecture Note Series, 66, 29-45, ISSN:2188-1200 (2015) M305

[14] Saeki, O., Wakayama, M., Yamamoto, M. (eds.): Study Group Workshop 2012, MI Lecture Note Series, 42, 93-121, ISSN:1881-4042 (2012) M305 
[15] Saeki, O., Okada, K., Takagi, T., Wakayama, M., Yamamoto, M. (eds.): Study Group Workshop 2013, MI Lecture Note Series, 52, 109-125, ISSN:2188-1200 (2013) M305

[16] Scott, D.J., Russell, K., Scheffer, J.: Multi-variable relationships in a batch annealing process. In: G.C. Wake (ed.), Proceedings of the 2006 Mathematics in Industry Study Group, pp. 33-55, Massey University, New Zealand ISBN 0-473-11068-7 (2007) M304

[17] Sweatman, W.L.: Mathematics-in-industry study group (MISG) steel projects from Australia and New Zealand, in M. Wakayama, R.S. Anderssen, J. Cheng, Y. Fukumoto, R. McKibbin, K. Polthier, T. Takagi, K.-C. Toh (eds.), The impact of applications on mathematics, Mathematics for Industry, 1, Springer, 307-322, ISBN 978-4-431-54907-9 (ebook), ISBN 978-4-431-54906-2 (hardcover) (2014) M304

[18] Sweatman, W.L., McGuinness, M. and Barry, S.I.: Heat transfer during annealing of steel coils. In: M. Günther, A. Bartel, M. Brunk, S. Schöps, M. Striebel (eds.), Progress in Industrial Mathematics at ECMI 2010, Mathematics in Industry 17, Springer Berlin Heidelberg, 303-309 doi:10.1007/978-3-642-25100-9_35 (2012) M304

[19] Sweatman, W.L., Wake, G.C., Fullard, L., Bruna, M.: Recovering vanadium during the production of steel from iron sand. ANZIAM J. 53, M1-M21 doi:10.21914/anziamj.v53i0.4674 (2012) M304

[20] von Kármán, T.: Beitrag zur Theorie des Walzvorganges, Z. angew Math. Mech. 5, 139 (1925) M310

[21] Wakayama, M., Fukumoto, Y., Takagi, T., Yamamoto, M. (eds.): Study Group Workshop 2010, MI Lecture Note Series, 27, 72-86, ISSN : 1881-4042 (2010) M305

[22] Wakayama, M., Fukumoto, Y., Takagi, T., Yamamoto, M. (eds.): Study Group Workshop 2011, MI Lecture Note Series, 33, 101-118, ISSN:1881-4042 (2011) M305 


\section{Author addresses}

1. Winston L. Sweatman, Centre for Mathematics in Industry, Institute of Natural and Mathematical Sciences, Massey University, Auckland, New ZeALAND.

mailto:w.sweatman@massey.ac.nz

2. Graham Weir, Institute of Fundamental Sciences, Massey University, Palmerston North, NeW ZEALAND.

mailto:grahamweir@xtra.co.nz

3. Anton Gulley, University of Auckland, New Zealand. mailto:gullant@gmail.com orcid:0000-0003-0759-1897

4. Daniel Clarke, University of Canterbury, New Zealand. mailto:daniel.clarke@pg.canterbury.ac.nz orcid:0000-0001-7668-2472

5. Yasuhide Fukumoto, Institute of Mathematics for Industry, Kyushu University, JAPAN. mailto:yasuhide@imi.kyushu-u.ac.jp

6. J. F. Harper, School of Mathematics and Statistics, Victoria University of Wellington, PO Box 600, Wellington 6140, NEW ZEALAND.

mailto: john.harper@vuw.ac.nz orcid:0000-0003-0030-7574

7. Sibylle Van Hove, University of Auckland, New ZeAland. mailto:svan511Caucklanduni.ac.nz 